\title{
Adsorption of Cd (II), Cu (II), and Zn (II) from Aqueous Solution onto Nitrogen-Functionalized Desmostachya bipinnata
}

\author{
Jagjit Kour, ${ }^{1}$ Puspa Lal Homagai, ${ }^{1}$ Massimo Cagnin, ${ }^{2}$ Antonio Masi, \\ Megh Raj Pokhrel, ${ }^{1}$ and Kedar Nath Ghimire ${ }^{1}$ \\ ${ }^{1}$ Central Department of Chemistry, Tribhuvan University, Kirtipur, P.O. Box 5506, Kathmandu, Nepal \\ ${ }^{2}$ Department of Agricultural Biotechnology, Padua University, Legnaro, Italy
}

Correspondence should be addressed to Jagjit Kour; jagjit_kour@hotmail.com

Received 7 December 2012; Revised 28 February 2013; Accepted 28 February 2013

Academic Editor: Concha Gimeno

Copyright (C) 2013 Jagjit Kour et al. This is an open access article distributed under the Creative Commons Attribution License, which permits unrestricted use, distribution, and reproduction in any medium, provided the original work is properly cited.

\begin{abstract}
A very simple means of nitrogen functional group grafting onto the backbone of Desmostachya bipinnata is investigated, which is a sacrificial herb in the south Asian region particular to Hindu religion. This natural biomaterial is found to be very effective for metal binding, after treatment with hydrazine monohydrate. The present study explores a comparison of amination processes by considering several options. The maximum metal loading capacities for $\mathrm{Cd}, \mathrm{Cu}$, and $\mathrm{Zn}$ were found to be $76.80 \mathrm{mg} / \mathrm{g}, 72.10 \mathrm{mg} / \mathrm{g}$, and $58.16 \mathrm{mg} / \mathrm{g}$, respectively. The kinetic evaluation indicated that the adsorption of $\mathrm{Cd}, \mathrm{Cu}$, and $\mathrm{Zn}$ onto the biomaterials followed the pseudo second-order rate equation.
\end{abstract}

\section{Introduction}

There is a growing concern in the development of bioadsorbents as the alternative to the synthetic chelating resins. Many research works are already in progress regarding how biomaterials can be made more effective [1]. Although various procedures have been used to create a suitable chelating medium onto the polymeric surface of biomaterials $[2,3]$, very little attention has been given to the functionalization of biomaterials. It is of common agreement based on the synthetic chelating materials that certain functional groups are selective for particular metal ions, as, for example, carboxylic functional moiety for lead [4], phosphoric for trivalent metal ions [5], and xanthate for mercury [1]. The same practical evidence has recently been applied in the development of functional biopolymer using several types of feed material like fruit waste [6], sugarcane waste [7], tea leaves $[8]$, plant $[9,10]$, and agricultural wastes [11].

Removal of toxic heavy metals from waste water is one of the most important environmental issues. Several physicochemical methods have been developed for the removal of heavy metals from wastewater, like extraction, ion exchange, chemical precipitation, and membrane separation processes. All these methods have some merits and demerits including incomplete metal removal, low selectivity, and production of large quantities of waste products that requires stringent disposal requirement. Conventional methods are limited by technical and economic barriers, especially when concentration of metals in waste water is low [12].

Activated carbon is most widely used as adsorbent material but high operating costs and difficult recycling processes have limited its application in large scale. On the other hand, biosorption has been recognized as a promising technology as an alternative to the conventional processes for the treatment of wastewater at trace levels of metal contaminants in industrial wastewater $[6,12,13]$.

In recent years, materials of biological origin have attracted many researchers. These include agricultural wastes, fruit peels, forestry, algal biomass, fungal biomass, and fishery products $[18-20]$. The most commonly used natural biosorbents are totally renewable low cost and their use and handling involve no additional risks [21-23]. Adsorption of heavy 
metals onto raw biosorbent has been found to be less effective owing to their limited exposed functional sites. Functional groups like carboxylate, hydroxyl, sulphate, phosphate, amide, and amine groups onto the biosorbents have been reported to be responsible for appreciable metal binding [13, 19, 24]. All biosorbents have an intrinsic sorption property which is dependent on the concentration and types of functional groups on the sorbent surfaces. As the density of these effective groups for metal binding is generally low, biosorbents do not show a high sorption capacity [6].

Several processes of surface modification have recently been investigated [25-31]. Among them, we have explored a better means of amine grafting technique onto $D$. bipinnata. It is a sacrificial wild herb freely grown on the river side and fields of Nepal, which is available at almost free of cost. It mainly contains cellulose (27.37\%), hemicelluloses (35.04\%), and lignin (7.64\%). In the present study, D. bipinnata has been modified using several aminating reagents, among which treatment with hydrazine monohydrate has been found to be very effective for the removal of Cd (II), Cu (II), and $\mathrm{Zn}$ (II) metal ions from wastewater.

\section{Materials and Method}

2.1. Chemicals. Standard stock solutions (1000 mg/L) of cadmium, copper, and zinc were prepared in Millipore milli$\mathrm{Q}$ deionised water from their nitrate and sulphate salts, respectively. All the working solutions of different concentrations were prepared by diluting standard stock solution with $0.1 \mathrm{M}$ nitric acid. In all working solutions 0.1 M HEPES (2[4-(2-Hydroxymethyl)-1-piperazinyl] ethanesulphonic acid) was used as the buffering agent [32]. The $\mathrm{pH}$ of the working solutions was adjusted by contacting with dilute nitric acid and sodium hydroxide solutions. All the reagents and chemicals used in this study were of analytical grade.

2.2. Preparation of Biomaterials. A typical herb, D. bipinnata, was collected from the southern part of Nepal. It was sundried, cut into small pieces, and then washed with tap water and finally with distilled water. After drying, the material was powdered with the aid of a mechanical grinder and sieved to pass through $212 \mu \mathrm{m}$ sieve. The powdered mass was treated with concentrated sulphuric acid and left for $24 \mathrm{~h}$. Acid treatment with such biomaterials create a suitable environment for its ring opening [33]. Then the biomaterial was washed with demonized water to remove excess acid and any other soluble substances until neutrality. The biomaterial was air- and sundried then finally dried in an oven at $70^{\circ} \mathrm{C}$ for $24 \mathrm{~h} .20 \mathrm{~g}$ of charred $D$. bipinnata (CDBP) was taken in a round bottom flask, treated with distilled water, and kept for swelling overnight. Then hydrazine monohydrate was added dropwise at room temperature and heated for $4 \mathrm{~h}$ at $80^{\circ} \mathrm{C}$ using water bath. The reaction scheme of biochar with hydrazine monohydrate is shown in Scheme 1. The mixture was cooled to room temperature and thoroughly washed with distilled water and finally with methanol. It was dried in an oven at $70^{\circ} \mathrm{C}$ for $24 \mathrm{~h}$. This final product is referred to as Aminated $D$. bipinnata (ADBP) and ready for adsorption experiments.

2.3. Study of Materials: SEM, Elemental Analysis, and DFTIR. The surface morphologies of raw biosorbent and aminated biosorbent were analyzed with the help of scanning electron microscope (SEM). The SEM microphotographs of biosorbent before chemical modification revealed clearly smooth and even surface as shown in Figure 1(a). The surface modification of biosorbent show the prominent changes like uneven microporous structure, rough and corroded surface morphology as shown in Figure 1(b) compared to the unmodified biosorbent. This result indicates chemical modification on the surface of biosorbent.

The elemental analysis of raw biosorbent shows $1.13 \%$ of nitrogen, whereas in aminated biosorbent percentage of nitrogen is found to be 7.56. This increase in percentage of nitrogen further supported the fact that introduction of amine group onto the biosorbent has taken place.

The spectrum of the RDBP was observed to be complex due to the numerous and multifarious functional groups on the surface of the biosorbent. The types of functional group present on the $D$. bipinnata were analyzed using diffuse reflectance infrared spectroscopy (DFTIR) (Harrick scientific corporation). The intense sharp adsorption peak at $3411 \mathrm{~cm}^{-1}$ in Figure 2 for RDBP can be assigned to the $\mathrm{O}-\mathrm{H}$ stretching vibration due to inter- and intramolecular hydrogen bonding of polymeric compounds like alcohols, phenols, and carboxylic acids as in cellulose, hemicellulose and lignin, indicating the presence of free hydroxyl groups on the biosorbent surface. The peak around $2926 \mathrm{~cm}^{-1}$ corresponds to $\mathrm{C}-\mathrm{H}$ stretching in $\mathrm{CH}_{2}$ and $\mathrm{CH}_{3}$ groups. Similarly, the peak around $1736 \mathrm{~cm}^{-1}$ corresponds to carbonyl $\mathrm{C}=\mathrm{O}$ stretching vibration. The peak around $1426-1377 \mathrm{~cm}^{-1}$ was due to $\mathrm{O}-\mathrm{H}$ bending vibration and $1169-1082 \mathrm{~cm}^{-1}$ was due to $\mathrm{C}-\mathrm{O}$ stretching vibration of alcohol. The polysaccharide presence is verified by the weak peak at $931 \mathrm{~cm}^{-1}$ attributed to the glycoside bonds in the polysaccharide structure $[34,35]$.

A sharp difference in IR spectra was noticed after the amination of biosorbent ADBP as shown in Figure 2. The intense sharp peak at $3411 \mathrm{~cm}^{-1}$ in RDBP has been shifted to $3392 \mathrm{~cm}^{-1}$ as a broad peak in ADBP, which may be due to the overlapping of the hydroxyl group with amine group. This is also an alternative proof for the introduction of amine group onto the surface of biosorbent.

2.4. Adsorption of Metal Ions. The adsorptions of metal ions were studied by batchwise method. Batch adsorption tests for different metal ions such as Cd (II), Cu (II), and Zn (II) removal were performed by keeping the respective metal ions concentration constant $(50 \mathrm{mg} / \mathrm{L})$ as the function of $\mathrm{pH}(\mathrm{pH}=$ $1,2,3,4,5,6$, and 7). All batch experiments were performed in $50 \mathrm{~mL}$ Erlenmeyer flasks taking $25 \mathrm{mg}$ of dried bioadsorbent (ADBP) with $20 \mathrm{~mL}$ of synthetic metal ions solutions. The $\mathrm{pH}$ of respective metal ions was maintained by contacting with dilute nitric acid and sodium hydroxide solutions and flasks were agitated in a shaker at $23^{\circ} \mathrm{C}$ (lab temp) at $150 \mathrm{rpm}$ for $24 \mathrm{~h}$ to attain equilibrium. After $24 \mathrm{~h}$, the solutions were filtered 


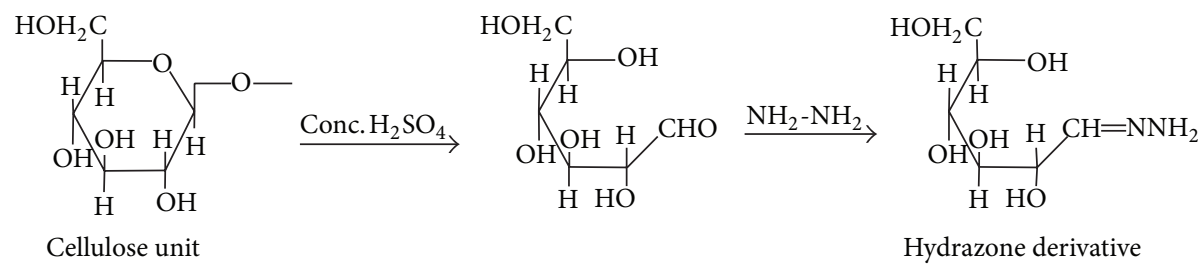

SCHEme 1: A plausible reaction scheme for functionalized biochar with hydrazine.

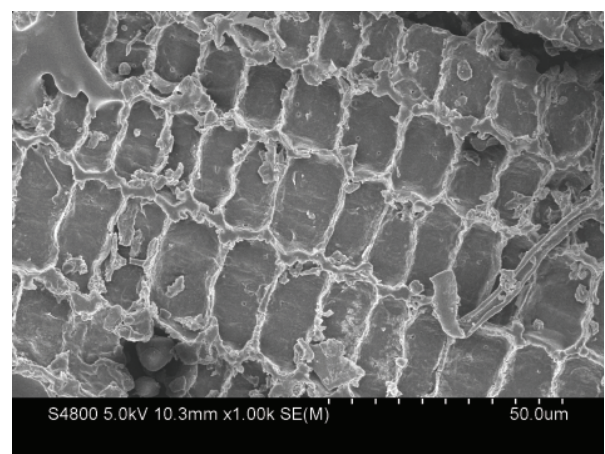

(a)

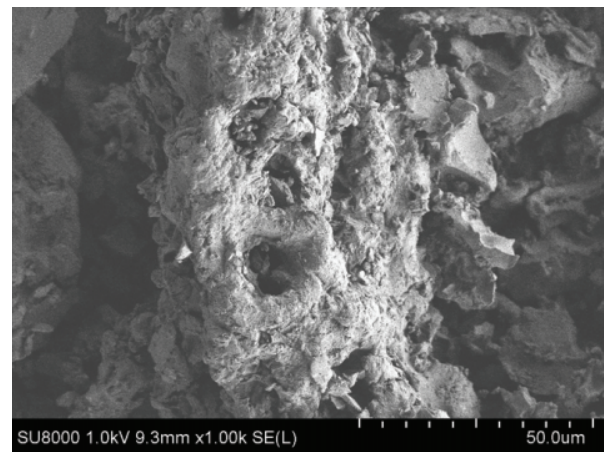

(b)

FIGURE 1: Scanning electron microscope (SEM) photographs of (a) Raw (RDBP) and (b) Aminated (ADBP) Desmostachya bipinnata.

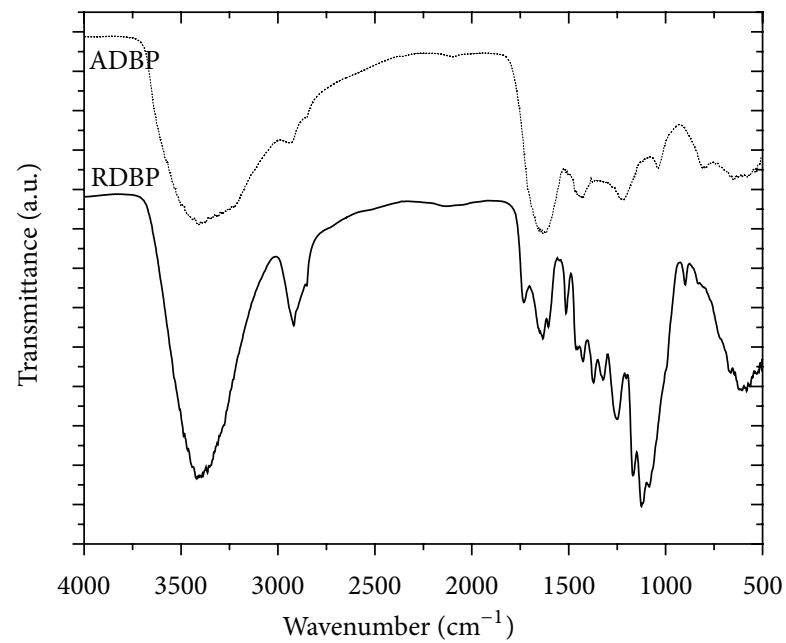

FIGURE 2: Diffuse reflectance infrared spectroscopy (DFTIR) Raw (RDBP) and Aminated (ADBP) Desmostachya bipinnata. through cellulose-free filter paper and their equilibrium concentrations were measured using (ICP-AES) inductively coupled plasma atomic emission spectrophotometer (SPECTRO, Analytical Instrument, Kleve, German). The adsorbed amount of metal ions was calculated from the decrease in the metal ions concentration from which percentage adsorptions were calculated as follows:

$$
A \%=\frac{C_{i}-C_{e}}{C_{i}} \times 100 .
$$

The metal uptake capacities of Aminated D. bipinnata (ADBP) for Cd (II), Cu (II), and Zn (II) were measured by batch experiment taking synthetic metal ions solutions of different concentration ranging from 25, 50, 100, 200, 400, 600 , and $800 \mathrm{mg} / \mathrm{L}$ at their optimum $\mathrm{pH}(6,5$, and 6 for $\mathrm{Cd}$, $\mathrm{Cu}$ and, $\mathrm{Zn}$, resp.). The sorption capacity of metal ions is the concentration of the metal ions onto the adsorbent, which can be calculated from the mass balance principle:

$$
q=\frac{C_{i}-C_{e}}{W} \times \frac{L}{1000} .
$$

In (1) and (2), $q$ represents the amount of metal uptake per unit mass of the adsorbent $(\mathrm{mg} / \mathrm{g}), L$ is the volume of the test solution $(\mathrm{mL}), W$ is the dry mass of the adsorbent $(\mathrm{g})$, and $C_{i}$ and $C_{e}$ are the initial and final concentrations $(\mathrm{mg} / \mathrm{L})$, respectively. For kinetic study, working solutions of respective metal ions of $50 \mathrm{mg} / \mathrm{L}$ were taken at their optimum $\mathrm{pH}$. The metal ions concentrations were measured at 14 different contact times $(5,10,15,20,25,30,45,60,90,120,180,240,300$ and $360 \mathrm{~min}$ ). The amount of metal ions adsorbed at a certain time $t$ was calculated from the mass adsorption rates of metal ions onto the biosorbent.

\section{Results and Discussion}

3.1. Adsorption of Cd (II), Cu (II), and Zn (II) Metal Ions. The $\mathrm{pH}$ of aqueous solution has been considered as one of the important factors for adsorption, which eventually decides the surface properties of the adsorbents in terms of ionization of functional groups and surface charge. At low solution $\mathrm{pH}$, a large quantity of hydronium ions $\left(\mathrm{H}_{3} \mathrm{O}^{+}\right)$in solution will compete with the metal ions for binding on the functional groups onto the adsorbent surface. Hence, there would be a decrease in adsorption of metal ions. But the adsorption of metal ions increases with the increase in $\mathrm{pH}$, due to the decrease in competition between hydronium ions $\left(\mathrm{H}_{3} \mathrm{O}^{+}\right)$ and metal species for the active sites on the sorbent surface; 
however, a decrease in adsorption will be observed after a certain $\mathrm{pH}$ owing to the hydrolysis of metal ions as well as the increased concentration of hydroxyl ions or anionic species in the medium. The maximum adsorptions of $\mathrm{Cd}$ (II), $\mathrm{Cu}$ (II), and $\mathrm{Zn}$ (II) metal ions were found at their optimum $\mathrm{pH}$ value 6,5, and 6, respectively, as shown in Figure 3. The small decreases in the removal of metal ions at higher $\mathrm{pH}$ values were due to the formation of hydroxides of the respective metal ions. The microprecipitations of $\mathrm{Cd}(\mathrm{OH})_{2}, \mathrm{Cu}(\mathrm{OH})_{2}$, and $\mathrm{Zn}(\mathrm{OH})_{2}$ were observed at $\mathrm{pH} 7.2,7$, and 7.5, respectively, from blank tests (no adsorbent). This may happen due to the decrease in solubility of $\mathrm{Cd}(\mathrm{OH})_{2}, \mathrm{Cu}(\mathrm{OH})_{2}$, and $\mathrm{Zn}(\mathrm{OH})_{2}$ metal ions. The optimal $\mathrm{pH}$ values 6,5 , and 6 were considered to be appropriate for all the adsorption experiments for $\mathrm{Cd}$ (II), Cu (II), and Zn (II) metal ions as depicted in Figure 3, respectively. The maximum adsorption capacity of the aminated biosorbents for respective metal ions was investigated at different metal ions concentrations ranging from 25 to $800 \mathrm{mg} / \mathrm{L}$ as shown in Figure 4 and the sorption isotherms were evaluated using the most used linearized Langmuir model represented by the following equation:

$$
\frac{C_{e}}{q_{e}}=\frac{1}{q_{m} b}+\frac{C_{e}}{q_{m}}
$$

where $q_{e}(\mathrm{mg} / \mathrm{g})$ is the amount of adsorbed metal ions per gram of adsorbent, $C_{e}(\mathrm{mg} / \mathrm{L})$ is the residual concentration of metal ions after adsorption, $q_{m}(\mathrm{mg} / \mathrm{g})$ is the maximum adsorption capacity, and $b(\mathrm{~L} / \mathrm{g})$ is the binding constant. The Langmuir constant and its correlation coefficients evaluated from the isotherms for $\mathrm{Cd}, \mathrm{Cu}$, and $\mathrm{Zn}$ metal ions are given in Table 1. The correlation coefficient $\left(R^{2}\right)$ of the Langmuir plot is high which suggests that the equilibrium adsorption of respective metal ions onto the biosorbent could be best described with the Langmuir (isotherm) adsorption equation. The maximum amounts of metal ions adsorbed $\left(q_{m}\right)$ based on experimental data were $76.80 \mathrm{mg} / \mathrm{g}, 72.10 \mathrm{mg} / \mathrm{g}$, and $58.16 \mathrm{mg} / \mathrm{g}$ for $\mathrm{Cd}, \mathrm{Cu}$, and $\mathrm{Zn}$, respectively. Freundlich adsorption isotherm did not fit the experimental adsorption data well (result not shown). On the other hand, the theoretical monolayer capacities $\left(q_{\max }\right)$ of the respective metal ions based on the Langmuir adsorption equation were found to be $83.33 \mathrm{mg} / \mathrm{g}, 76.92 \mathrm{mg} / \mathrm{g}$, and $62.50 \mathrm{mg} / \mathrm{g}$, respectively, which indicated that the active sites of biosorbent are constant and independent of the metal solutions used. The values of $b$ are indicative of the affinity of the sorbent by the sorbate, and high values of $b$ are associated with high metal adsorbed/ desorbed ratio. The constant $b$ is higher for $\mathrm{Cd}$ than for $\mathrm{Cu}$ and $\mathrm{Zn}$ indicating that it has high affinity towards the active sites of the adsorbent. The above results are in close agreement with each other suggesting that heavy metals can be quantitatively sequestered onto the Aminated $D$. bipinnata (ADBP).

The adsorption capacity of biosorbent was found to be increased with an increase in the initial concentration of metal ions in solution. In all cases when the initial concentration exceeded from $400 \mathrm{mg} / \mathrm{L}$ to $600 \mathrm{mg} / \mathrm{L}$, the adsorption capacity remained almost constant. This is because during the initial concentration of $400 \mathrm{mg} / \mathrm{L}-600 \mathrm{mg} / \mathrm{L}$, the active sites

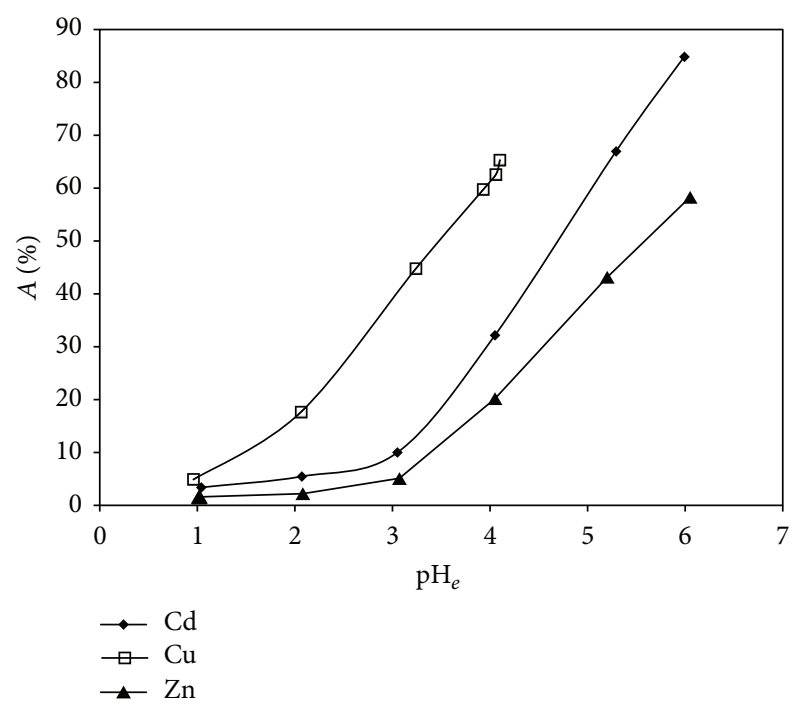

FIgURE 3: Effect of $\mathrm{pH}$ in the adsorption of $\mathrm{Cd}$ (II), $\mathrm{Cu}$ (II), and $\mathrm{Zn}$ (II) onto Aminated Desmostachya bipinnata (ADBP).

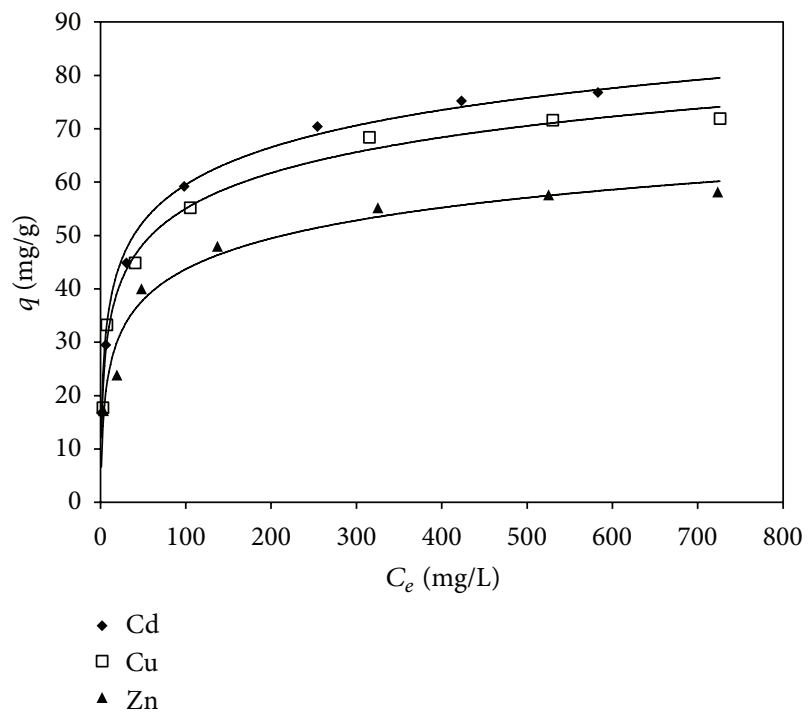

FIgURE 4: Adsorption isotherm for the Cd (II), Cu (II), and Zn (II) onto Aminated Desmostachya bipinnata (ADBP).

TABLE 1: Langmuir adsorption model parameters and experimental $q_{\max }$.

\begin{tabular}{lcccc}
\hline Metal ions & $\begin{array}{c}q_{\max }(\mathrm{mg} / \mathrm{g}) \\
\text { Langmuir model }\end{array}$ & $\begin{array}{c}q_{\max }(\mathrm{mg} / \mathrm{g}) \\
\text { Experimental }\end{array}$ & $b(\mathrm{~L} / \mathrm{g})$ & $R^{2}$ \\
\hline $\mathrm{Cd}(\mathrm{II})$ & 83.33 & 76.80 & 0.052 & 0.998 \\
$\mathrm{Cu}(\mathrm{II})$ & 76.92 & 72.10 & 0.049 & 0.999 \\
$\mathrm{Zn}$ (II) & 62.50 & 58.16 & 0.037 & 0.999 \\
\hline
\end{tabular}

of the adsorbents were almost gradually filled by metal ions, and hence the adsorption activity of adsorbent is limited. So further increase in initial concentration of metal ions results in no more adsorption, due to unavailability of adsorption sites. So $400 \mathrm{mg} / \mathrm{L}-600 \mathrm{mg} / \mathrm{L}$ was found to be the optimum 
TABLE 2: Sorption kinetics of pseudo second order for metal ions.

\begin{tabular}{lccc}
\hline Metal ions & $q_{e}(\mathrm{mg} / \mathrm{g})$ & $R^{2}$ & $K_{2}(\mathrm{~g} / \mathrm{mg} / \mathrm{min})$ \\
\hline $\mathrm{Cd}(\mathrm{II})$ & 25.68 & 0.999 & $2.81 \times 10^{-3}$ \\
$\mathrm{Cu}(\mathrm{II})$ & 33.84 & 0.998 & $0.80 \times 10^{-3}$ \\
$\mathrm{Zn}(\mathrm{II})$ & 39.03 & 0.997 & $1.59 \times 10^{-3}$ \\
\hline
\end{tabular}

concentration of metal ions for effective adsorption. In all cases correlation coefficient $\left(R^{2}\right)$ value was found to be 0.99 indicating that the Langmuir isotherm model fitted well in all cases as shown in Figure 5. No information is available in the literature on the isotherm of $\mathrm{Cd}, \mathrm{Cu}$, and $\mathrm{Zn}$ adsorption by $D$. bipinnata to compare with our findings.

Several kinetic models are described to investigate the reaction order in sorption systems. However, over the past few years, pseudo second-order kinetic model has been considered to be among the most appropriate. The experimental data showed an increase in adsorption percentage with the increase in time from $5 \mathrm{~min}$ to $120 \mathrm{~min}$ and then it became almost constant as shown in Figure 6. All the kinetic data of the respective metal ions were tested using the pseudo firstorder and pseudo second-order rate equation. In case of the first-order rate equation, data were poorly fitted (data and figure not given) and the Lagergren correlation coefficient $\left(R^{2}\right)$ value was very low. Therefore, pseudo second-order kinetic model has been used to evaluate the experimental kinetics adsorption data given by Ho and McKay [36]:

$$
\frac{t}{q_{t}}=\frac{1}{k_{2} q_{e}^{2}}+\frac{t}{q_{e}}
$$

where $q_{t}(\mathrm{mg} / \mathrm{g})$ is the amount of the adsorption at time $t$ ( $\mathrm{min})$ and $k_{2}(\mathrm{~g} / \mathrm{mg} / \mathrm{min})$ is the rate constant of the pseudo second-order kinetic adsorption. The straight line plots of $t / q_{t}$ versus $t$, as shown in Figure 7, have been used to obtain the rate parameters. The calculated values of $k_{2}, q_{e}$, and $R^{2}$ are given in Table 2 .

The results indicated that the second-order rate constant $k_{2}$ decreased with an increase in the initial metal ions concentration. From Table 1 , it is found that the calculated $q_{e}$ values agreed well with those of experimentally obtained $q_{e}$ for the pseudo second-order model. The $R^{2}$ values for all metal ions concentration obtained by fitting the experimental data to (4) were close to 1.0, which indicates the applicability of the model for the entire adsorption process and also confirmed the chemisorptions of the respective metal ions onto the ADBP.

\subsection{Comparison of Metal Loading Capacities of Different Bio-} sorbents. The metal loading capacity of ADBP was compared with different biosorbents reported in the literatures and the values are given in Table 3 .

\section{Conclusions}

Nitrogen functional groups were successfully introduced onto the polymeric surface of the biosorbent based on

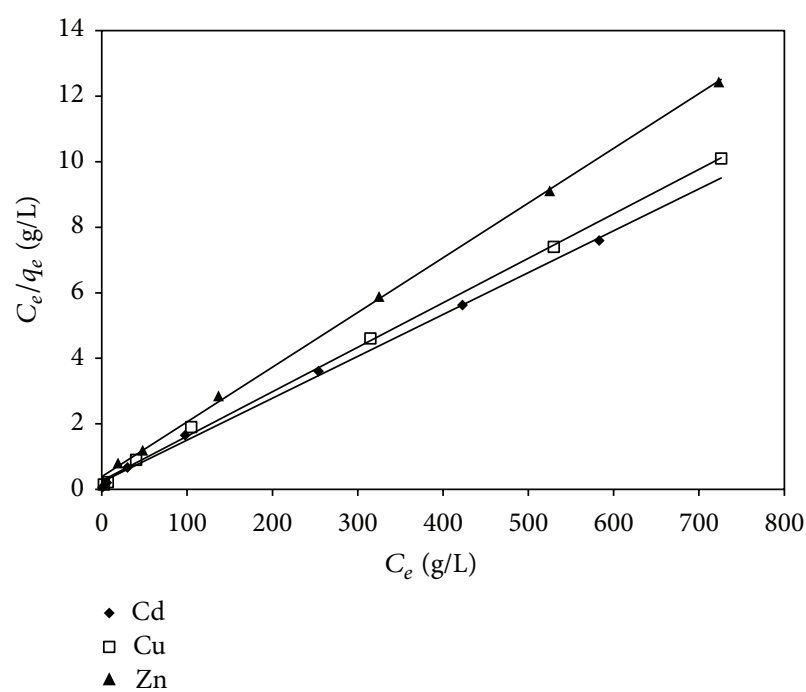

FIGURE 5: Langmuir plot for the adsorption of Cd (II), Cu (II), and Zn (II) onto Aminated Desmostachya bipinnata (ADBP).

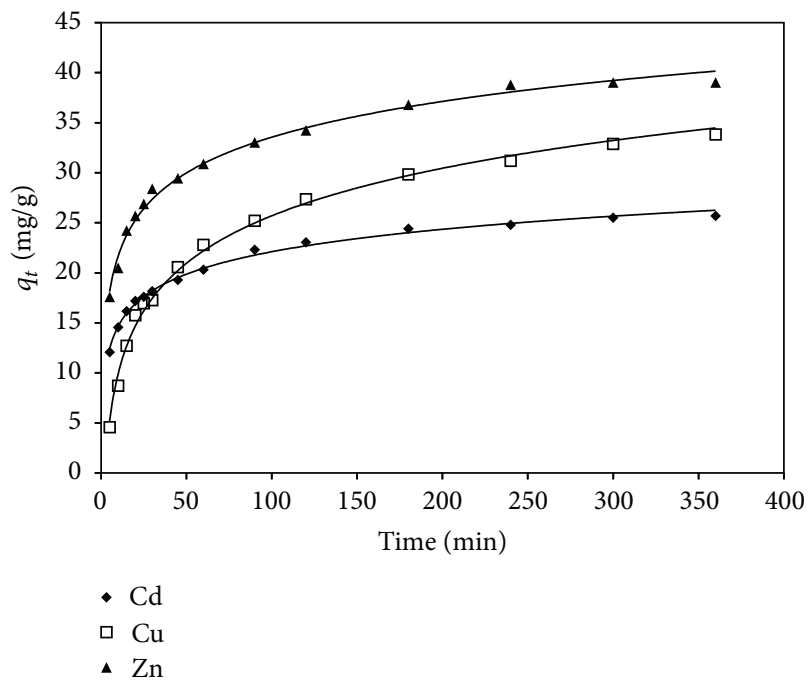

Figure 6: Adsorption kinetics of Cd (II), Cu (II), and Zn (II) onto Aminated Desmostachya bipinnata (ABDP).

TABLE 3: Comparison of metal loading capacities (mg/g) of different biosorbents for the removal of Cd (II), Cu (II), and $\mathrm{Zn}$ (II) metal ions reported in the literatures.

\begin{tabular}{lcccc}
\hline Adsorbents & Cd (II) & $\mathrm{Cu}$ (II) & Zn (II) & References \\
\hline $\begin{array}{l}\text { Desmostachya bipinnata } \\
\text { Saw dust }\end{array}$ & 76.80 & 72.10 & 58.16 & This study \\
(Cedrus deodara wood) & 73.62 & - & - & {$[14]$} \\
Saw dust (Poplar tree) & - & 13.95 & - & {$[15]$} \\
Saw dust (Poplar tree) & - & - & 15.8 & {$[16]$} \\
Sunflower stalk & 42.18 & 29.30 & 30.73 & {$[9]$} \\
Arundo donax L stem & 5.7 & - & - & {$[10]$} \\
Jute fibres & - & 8.40 & 8.02 & {$[17]$} \\
\hline
\end{tabular}




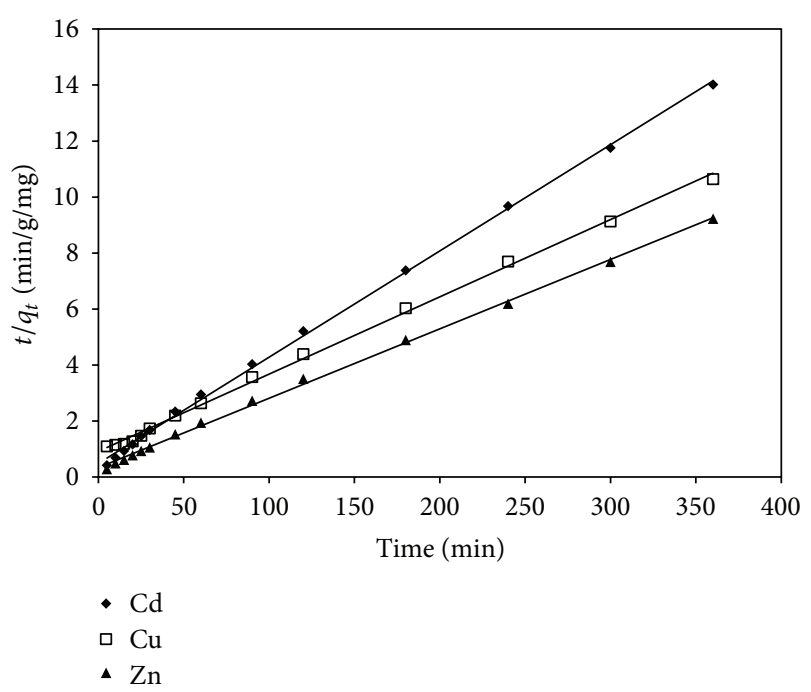

Figure 7: Pseudo second-order kinetic model in the adsorption of $\mathrm{Cd}$ (II), Cu (II), and Zn (II) onto Aminated Desmostachya bipinnata (ADBP).

Desmostachya bipinnata by treating with hydrazine monohydrate. A new biosorbent is explored, which is easily available, cost effective, and ecofriendly. Batch adsorption experiment performed for adsorption isotherm and kinetic studies at their optimum $\mathrm{pH}$ revealed that ADBP has excellent adsorption capacities. FTIR, SEM, and elemental analysis suggested the introduction of amine groups onto the surface of biosorbent, which were responsible for the quantitative adsorption of the respective metal ions from waste water. However, further adsorption/desorption studies concerning the recovery and reuse of biosorbent should be carried out to investigate the cost effectiveness and potential application in the waste water treatment.

\section{Acknowledgments}

One of the authors J. Kour would like to thank the cultural and scientific agreement program between Padua University and Tribhuvan University (Professor Caravello and Professor Promod. K. Jha) for supporting this research work. The University Grant Commission, Bhaktapur, Nepal, is highly acknowledged for the Ph. D. fellowship.

\section{References}

[1] S. Babel and T. A. Kurniawan, "Low-cost adsorbents for heavy metals uptake from contaminated water: a review," Journal of Hazardous Materials, vol. 97, no. 1-3, pp. 219-243, 2003.

[2] A. Chergui, M. Z. Bakhti, A. Chahboub, S. Haddoum, A. Selatnia, and G. A. Junter, "Simultaneous biosorption of $\mathrm{Cu}^{2+}, \mathrm{Zn}^{2+}$ and $\mathrm{Cr}^{6+}$ from aqueous solution by Streptomyces rimosus biomass," Desalination, vol. 206, no. 1-3, pp. 179-184, 2007.

[3] U. Kumar and M. Bandyopadhyay, "Sorption of cadmium from aqueous solution using pretreated rice husk," Bioresource Technology, vol. 97, no. 1, pp. 104-109, 2006.
[4] R. P. Dhakal, K. N. Ghimire, K. Inoue, M. Yano, and K. Makino, "Acidic polysaccharide gels for selective adsorption of lead (II) ion," Separation and Purification Technology, vol. 42, no. 3, pp. 219-225, 2005.

[5] L. Fang, K. N. Ghimire, M. Kuriyama, K. Inoue, and K. Makino, "Removal of fluoride using some lanthanum(III)-loaded adsorbents with different functional groups and polymer matrices," Journal of Chemical Technology and Biotechnology, vol. 78, no. 10, pp. 1038-1047, 2003.

[6] M. Thirumavalavan, Y. L. Lai, L. C. Lin, and J. F. Lee, "Cellulosebased native and surface modified fruit peels for the adsorption of heavy metal ions from aqueous solution: langmuir adsorption isotherms," Journal of Chemical and Engineering Data, vol. 55, no. 3, pp. 1186-1192, 2010.

[7] O. Karnitz Jr., L. V. A. Gurgel, J. C. P. de Melo et al., "Adsorption of heavy metal ion from aqueous single metal solution by chemically modified sugarcane bagasse," Bioresource Technology, vol. 98, no. 6, pp. 1291-1297, 2007.

[8] A. H. Mahvi, D. Naghipour, F. Vaezi, and S. Nazmara, "Teawaste as an adsorbent for heavy metal removal from industrial wastewaters," American Journal of Applied Sciences, vol. 2, no. 1, p. 372, 2005.

[9] G. Sun and W. Shi, "Sunflower stalks as adsorbents for the removal of metal ions from wastewater," Industrial and Engineering Chemistry Research, vol. 37, no. 4, pp. 1324-1328, 1998.

[10] M. C. Basso, E. G. Cerrella, and A. L. Cukierman, "Lignocellulosic materials as potential biosorbents of trace toxic metals from wastewater," Industrial and Engineering Chemistry Research, vol. 41, no. 15, pp. 3580-3585, 2002.

[11] G. Moussavi and R. Khosravi, "Removal of cyanide from wastewater by adsorption onto pistachio hull wastes: parametric experiments, kinetics and equilibrium analysis," Journal of Hazardous Materials, vol. 183, no. 1-3, pp. 724-730, 2010.

[12] A. Witek-Krowiak, R. G. Szafran, and S. Modelski, "Biosorption of heavy metals from aqueous solutions onto peanut shell as a low-cost biosorbent," Desalination, vol. 265, no. 1-3, pp. 126-134, 2011.

[13] H. K. Alluri, S. R. Ronda, V. S. Settalluri, B. Jayakumar Singh, V. Suryanarayana, and P. Venkateshwar, "Biosorption: an ecofriendly alternative for heavy metal removal," African Journal of Biotechnology, vol. 6, no. 25, pp. 2924-2931, 2007.

[14] S. Q. Memon, N. Memon, S. W. Shah, M. Y. Khuhawar, and M. I. Bhanger, "Sawdust-A green and economical sorbent for the removal of cadmium (II) ions," Journal of Hazardous Materials, vol. 139, no. 1, pp. 116-121, 2007.

[15] F. N. Acar and Z. Eren, "Removal of $\mathrm{Cu}(\mathrm{II})$ ions by activated poplar sawdust (Samsun Clone) from aqueous solutions," Journal of Hazardous Materials, vol. 137, no. 2, pp. 909-914, 2006.

[16] M. Š́́iban, M. Klašnja, and B. Škrbić, "Modified softwood sawdust as adsorbent of heavy metal ions from water," Journal of Hazardous Materials, vol. 136, no. 2, pp. 266-271, 2006.

[17] S. R. Sukla and R. S. Pai, "Adsorption of Cu (II), Ni (II) and Zn (II) on modified jute fibres," Bioresource Technology, vol. 96, no. 13, pp. 1430-1438, 2005.

[18] S. Deng and Y. P. Ting, "Fungal biomass with grafted poly(acrylic acid) for enhancement of $\mathrm{Cu}(\mathrm{II})$ and $\mathrm{Cd}(\mathrm{II})$ biosorption," Langmuir, vol. 21, no. 13, pp. 5940-5948, 2005.

[19] Y. S. Yun, D. Park, J. M. Park, and B. Volesky, "Biosorption of trivalent chromium on the brown seaweed biomass," Environmental Science and Technology, vol. 35, no. 21, pp. 4353-4358, 2001. 
[20] K. M. Khoo and Y. P. Ting, "Biosorption of gold by immobilized fungal biomass," Biochemical Engineering Journal, vol. 8, no. 1, pp. 51-59, 2001.

[21] S. A. Ahmed, "Batch and fixed-bed column techniques for removal of $\mathrm{Cu}(\mathrm{II})$ and $\mathrm{Fe}(\mathrm{III})$ using carbohydrate natural polymer modified complexing agents," Carbohydrate Polymers, vol. 83, no. 4, pp. 1470-1478, 2011.

[22] S. Chen, Q. Yue, B. Gao, and X. Xu, "Equilibrium and kinetic adsorption study of the adsorptive removal of $\mathrm{Cr}(\mathrm{VI})$ using modified wheat residue," Journal of Colloid and Interface Science, vol. 349, no. 1, pp. 256-264, 2010.

[23] G. Blázquez, F. Hernáinz, M. Calero, and L. F. Ruiz-Núñez, "Removal of cadmium ions with olive stones: the effect of somes parameters," Process Biochemistry, vol. 40, no. 8, pp. 2649-2654, 2005.

[24] T. Tan and P. Cheng, "Biosorption of metal ions with Penicillium chrysogenum," Applied Biochemistry and Biotechnology A, vol. 104, no. 2, pp. 119-128, 2003.

[25] P. L. Homagai, H. Paudyal, and K. N. Ghimire, "Adsorption kinetics of $\mathrm{Pb}$ (II), Cd (II) and Fe (III) onto saponified apple waste," Journal of Nepal Chemical Society, vol. 23, pp. 102-105, 2009.

[26] K. N. Ghimire, K. Inoue, K. Makino, and T. Miyajima, "Adsorptive removal of arsenic using orange juice residue," Separation Science and Technology, vol. 37, no. 12, pp. 2785-2799, 2002.

[27] P. L. Homagai, K. N. Ghimire, and K. Inoue, "Preparation and characterization of charred xanthated sugarcane bagasse for the separation of heavy metals from aqueous solutions," Separation Science and Technology, vol. 46, no. 2, pp. 330-339, 2011.

[28] N. Sankararamakrishnan and R. Sanghi, "Preparation and characterization of a novel xanthated chitosan," Carbohydrate Polymers, vol. 66, no. 2, pp. 160-167, 2006.

[29] S. Chakraborty and V. Tare, "Role of various parameters in synthesis of insoluble agrobased xanthates for removal of copper from wastewater," Bioresource Technology, vol. 97, no. 18, pp. 2407-2413, 2006.

[30] A. Kumar, N. N. Rao, and S. N. Kaul, "Alkali-treated straw and insoluble straw xanthate as low cost adsorbents for heavy metal removal-preparation, characterization and application," Bioresource Technology, vol. 71, no. 2, pp. 133-142, 2000.

[31] S. Deng, R. Bai, and J. P. Chen, "Aminated polyacrylonitrile fibers for lead and copper removal," Langmuir, vol. 19, no. 12, pp. 5058-5064, 2003.

[32] K. N. Ghimire, K. Inoue, K. Ohto, and T. Hayashida, "Adsorptive separation of metallic pollutants onto waste seaweeds, Porphyra Yezoensis and Ulva Japonica," Separation Science and Technology, vol. 42, no. 9, pp. 2003-2018, 2007.

[33] R. T. Morrison and R. N. Byod, Organic Chemistry, PrenticcHall, New Delhi, India, 6th edition, 1994.

[34] R. M. Silverstein, G. C. Bassler, and T. C. Morril, Spectrometric Identification of Organic Compounds, John Willy and Sons, New York, NY, USA, 4th edition, 1981.

[35] R. L. Shriner, C. K. F. Hermann, T. C. Morrill, D. Y. Curtin, and R. C. Fuson, The Systematic Identification of Organic Compounds, Wiley, New York, NY, USA, 7th edition, 1998.

[36] Y. S. Ho and G. McKay, "Pseudo-second order model for sorption processes," Process Biochemistry, vol. 34, no. 5, pp. 451-465, 1999. 

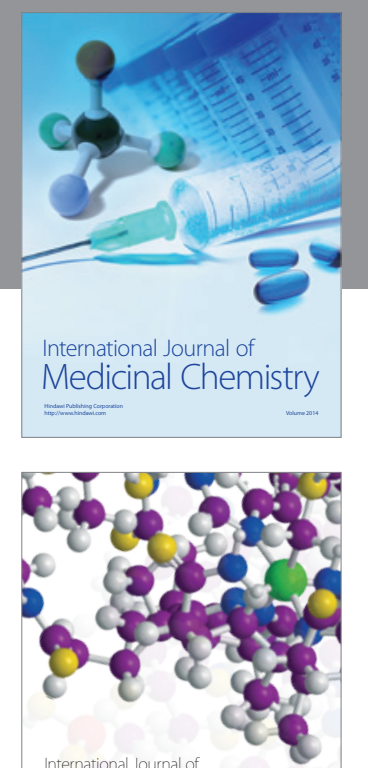

\section{Carbohydrate} Chemistry

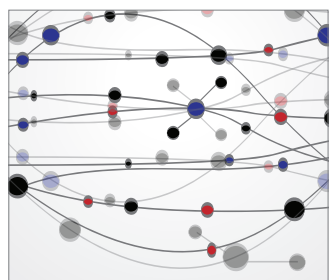

The Scientific World Journal
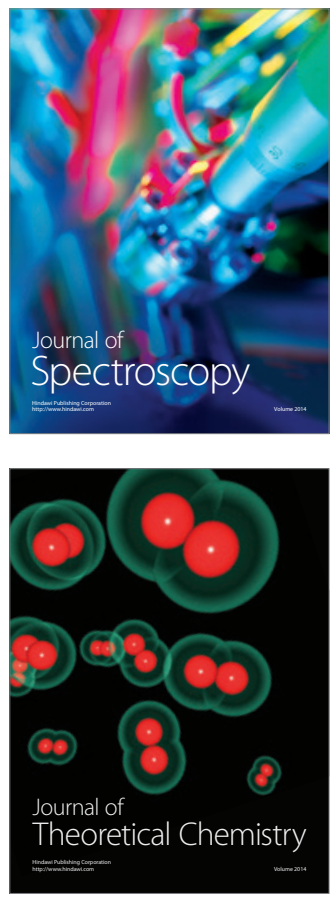
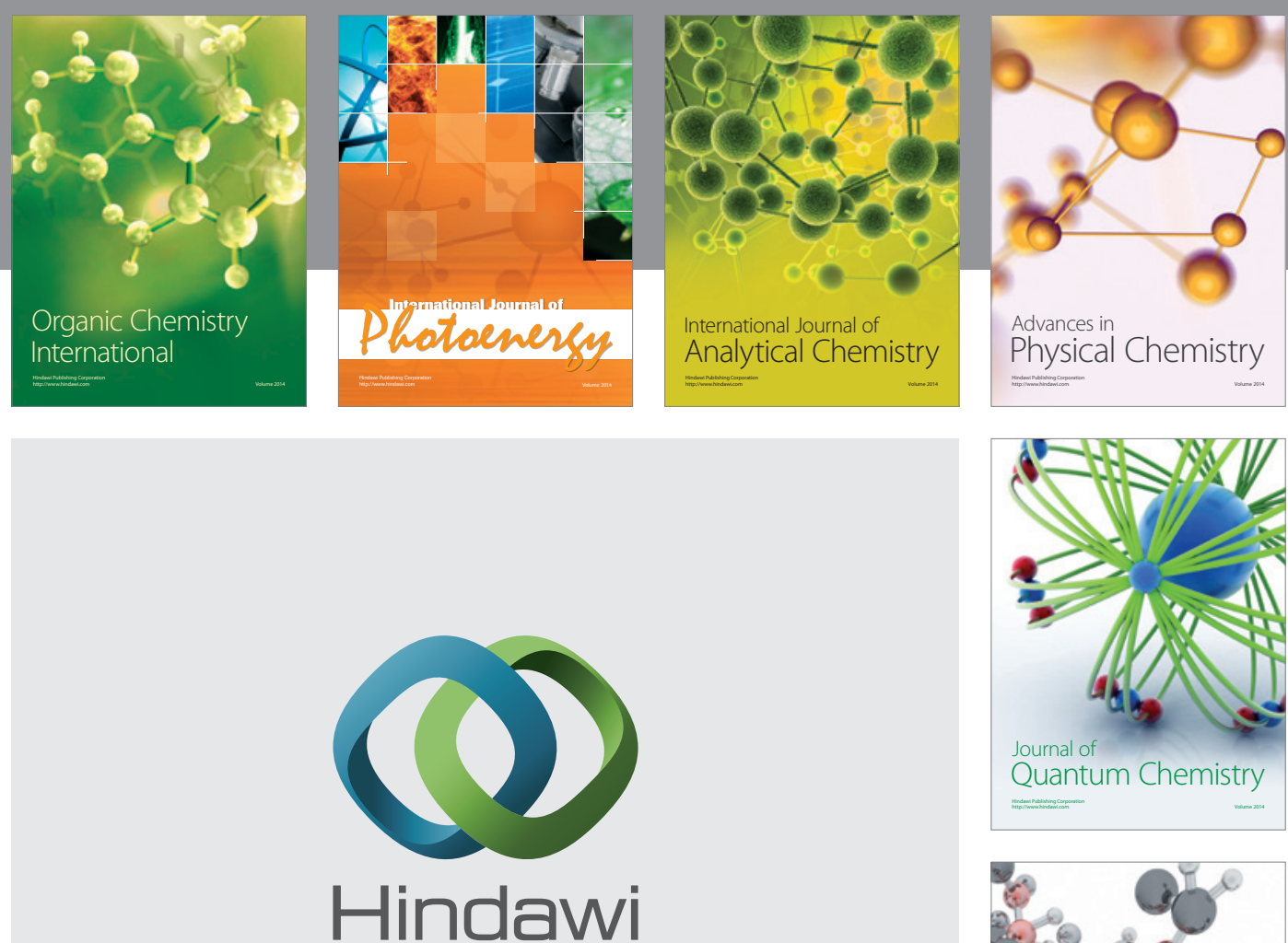

Submit your manuscripts at

http://www.hindawi.com

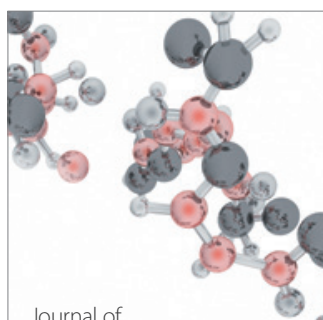

Analytical Methods

in Chemistry

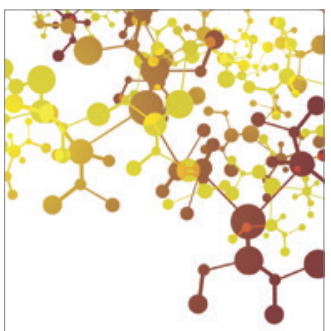

Journal of

Applied Chemistry

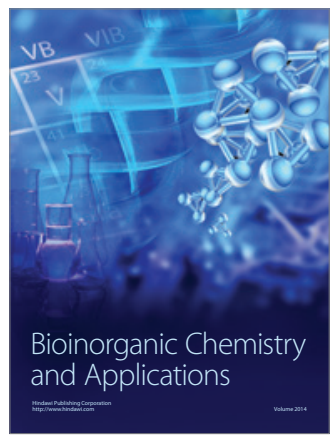

Inorganic Chemistry
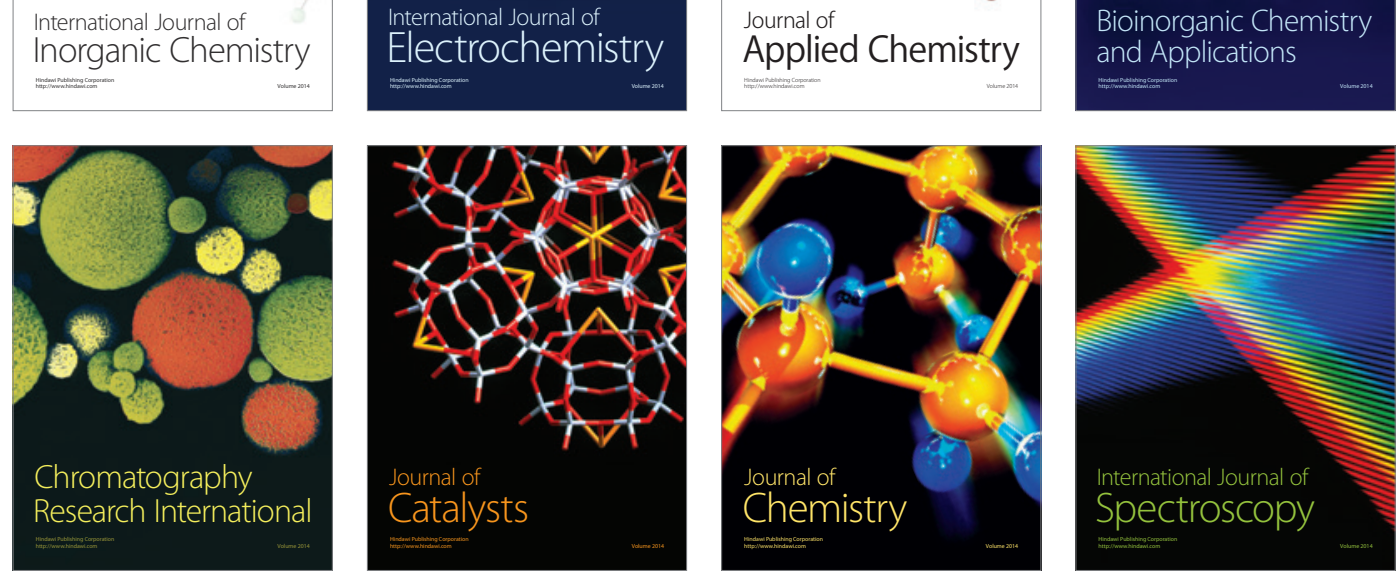